\title{
TLC at APSA: Take Two at APSA Annual Meeting in Washington, DC
}

\author{
Bethany Blackstone, University of North Texas \\ Sherri L. Wallace, University of Louisville
}

$\mathrm{T}$ he second annual Teaching and Learning Conference (TLC) at APSA, held on August 31, 2019, was a resounding success. The one-day conference-within-a-conference built on the larger conference theme by highlighting political science education in the time of resurgent populism and privilege. The meeting attracted over 200 attendees, including over 150 first-time participants. The TLC at APSA continues the historical legacy of the stand-alone Teaching and Learning Conference by bringing together scholareducators in all fields of political science from across the globe to engage, share, and advance their pedagogical research, knowledge, and skills. By supporting the continuation of an annual TLC at APSA, APSA facilitates increased opportunities for professional development and advancement in the areas of teaching and learning for all APSA members. The TLC at APSA offers an unparalleled opportunity to expand participation in the scholarly community surrounding teaching and learning. The conference makes it easy for APSA-goers to see what TLC is all about without incurring the full cost of attendance at another conference. Of course, TLC at APSA is a supplement to, not a replacement for the biennial stand-alone TLC meeting. Many significant and lasting contributions to the discipline and political science education have resulted from collaborations formed and shared among attendees at TLC and TLC at APSA and we look forward to the role that both conference formats will play in advancing the study and practice of political science education. The next TLC will be held in Albuquerque, New Mexico, February 7-9, 2020, with the theme "Teaching to Empower Students."

\section{CONFERENCE STRUCTURE}

The design of 2018's inaugural TLC at APSA allowed attendees to experience a short version of the workshop format adopted by the biennial TLC. It incorporated "teaching cafés, workshops and themed tracks that facilitated not only deeper engagement with the [SoTL] but also acquisition of innovative tools for teaching political science, meals including a breakfast with a plenary speaker, a hosted

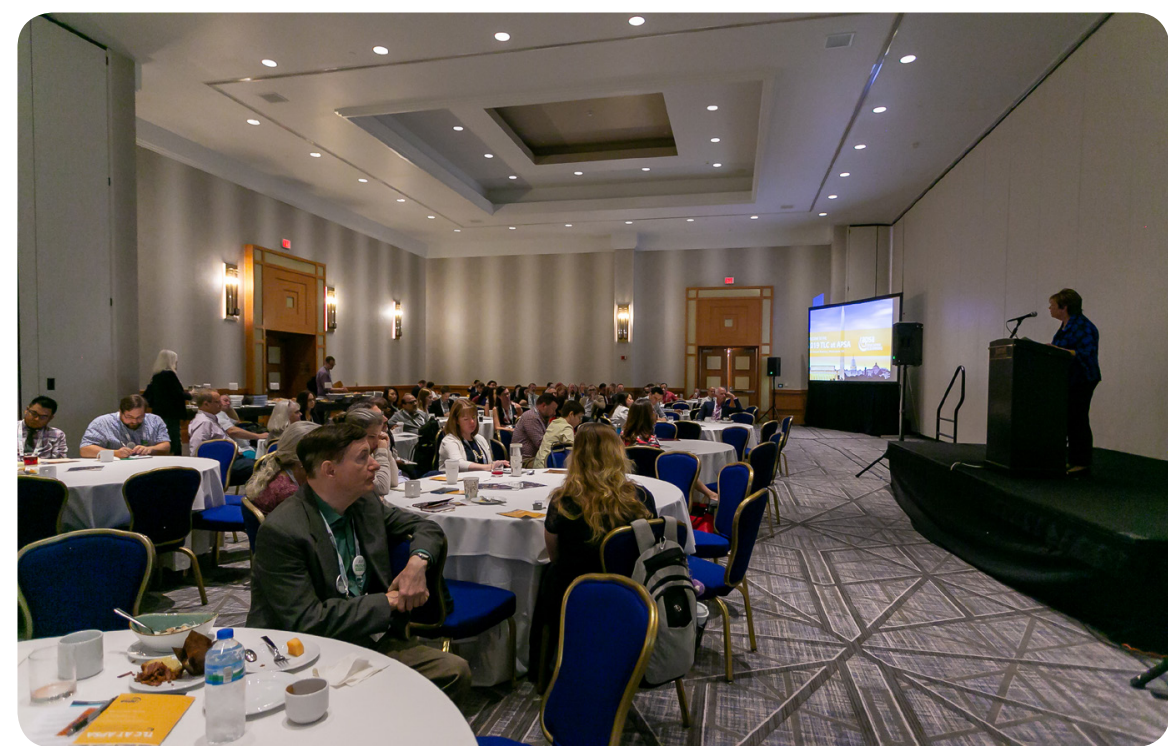

The second annual TLC at APSA event, hosted at the Marriott Wardman Park hotel during the 2019 APSA Annual Meeting in Washington, DC.

lunch, and closing reception," (Rios Millett McCartney and Van Vechten, 2019: 157). While the 2019 program committee was not bound to this format, based on feedback from 2018 conference attendees and consultation with Tanya Schwarz, APSA's Director of Teaching and Learning, the 2019 committee chose to maintain most of the same features. The 2019 schedule eliminated the teaching café and replaced it with a theme panel during the luncheon to allow all presentation slots on the TLC at APSA schedule to align with those of the general APSA schedule. The program committee also incorporated a new track on diversity, equity, and inclusion in response to the large number of excellent proposals related to these topics.

Bethany Blackstone (University of North Texas) and Sherri L. Wallace (University of Louisville) were co-chairs of the program committee. The program committee also included the following members and track moderators: Shane Nordyke, University of South Dakota (track moderator: technology and innovative pedagogy in the classroom), Alison Rios Millett McCartney, Towson University (track moderator: diversity, equity, and inclusion), Joseph Roberts, Roger Williams University (track moderator: simulations \& games), and Dick Simpson, University of Illinois, Chicago (track moderator: civic engagement education).
The program committee reviewed the large volume of proposals and selected the top proposals that best aligned with the conference theme and addressed emergent issues in political science instruction. For continuity, each committee member served as a track moderator and was responsible for organizing and facilitating two track-connected panel sessions, which yielded four papers/ presentations per session.

The day began with a breakfast keynote address, "Advancing Liberal Education and Civic Engagement Amidst Critics, Skeptics and Trolls in a Post-Truth Era," delivered by Lynn Pasquerella, president of the Association of American Colleges and Universities. The four thematic morning workshops, offered simultaneously, were chosen to showcase dynamic and innovative strategies, techniques, or tools for use in a variety of educational settings. Meira Levinson (Harvard University) and Jacob Zadorozny Fay (Bowdoin College) presented techniques for "Teaching Political Science with Normative Case Studies." James N. Druckman (Northwestern University), Jaime E. Settle (College of William \& Mary), Daniel L. Nielson, (Brigham Young University), Cheryl Boudreau, (University of California, Davis) and Megan Becker, (University of Southern California) introduced tools for "Teaching Experimental 


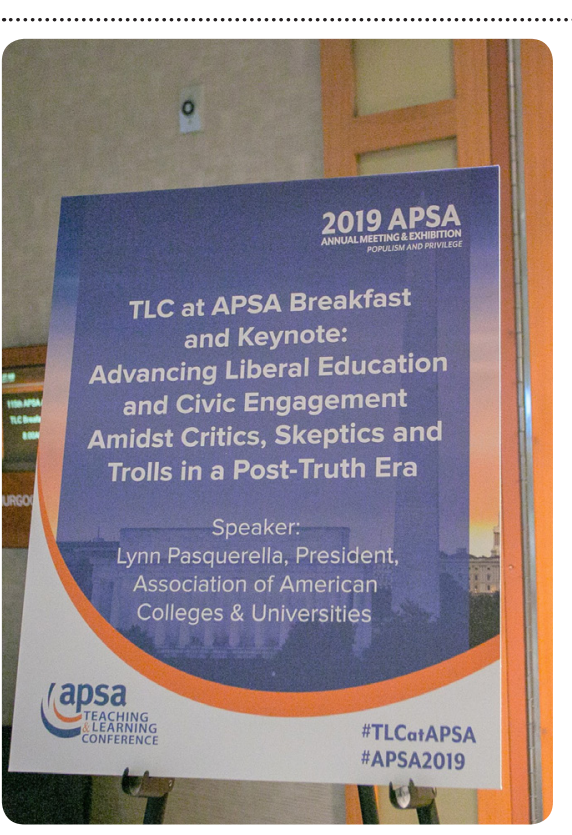

Methods to Undergraduates." The workshop "Podcasting Political Science: How to Start a Podcast, and Why You Should" was led by Michael Bossetta (University of Copenhagen), and a large panel that showcased tools for "Nonpartisan Student Voter Education and Engagement-Putting Research into Action" was led by Elizabeth C. Matto (Rutgers University, New Brunswick), Jennifer Domagal-Goldman (ALL IN Campus Democracy Challenge), Allison Rank (SUNY, Oswego State), Edie N. Goldenberg (University of Michigan, Ann Arbor), Dick Simpson (University of Illinois, Chicago), Elizabeth A. Bennion (Indiana University, South Bend), Robert W. Glover (University of Maine), and Mike Burns (Campus Vote Project). To support participants of the latter workshop, a shared Google drive was created of relevant research, reports, and planning materials. These resources will serve as an ongoing toolkit for scholar-practitioners as they work to promote student voter education and engagement.

The CQ Press-sponsored buffet luncheon featured a theme panel on "Online Learning and a Global Student Body," given the universal significance of the topic for all educators. This panel consisted of global scholars from the United Kingdom and United States, including Ashley Cox (School of Oriental and African Studies, University of London), Nanette Levinson (School of International Service at American University), Paul Kreutzer (United States Department of State), and Carlos Salvador Zepeda (School of Oriental and African Studies, University of London).
Participants spent the afternoon in traditional panel sessions within the four conference tracks-civic engagement education; simulations and games; technology and innovative pedagogy in the classroom; and diversity, equity, and inclusion. The summaries for each track follow.

\section{CIVIC ENGAGEMENT EDUCATION Elizabeth Bennion, Elizabeth Matto, and Andrew Smith}

As the conference's theme suggests, a central topic of discussion in the civic engagement education track was how to educate students on politics and civic engagement in an era of "fake news," greater friction between groups of different political and social persuasions, and the rise of populist figures challenging the status quo. Jessica Genauer (Australia National University) stressed the importance of teaching competencies, including information literacy and critical thinking, including an awareness of one's own cognitive biases. Active learning strategies can promote such skills, while also developing cultural awareness and an understanding of the policy environment. Genauer uses self-assessments, experiments designed to reveal students' own biases in information consumption, and simulations of real-world policy events to develop critical competencies.

Janet Donovan (University of Colorado, Boulder) continued this theme by focusing on information literacy. To improve students' ability to dissect news stories and separate facts from opinions and beliefs, Donavan recommended dividing students into groups to answer questions about the bias present in specific news articles before attempting to create unbiased news stories of their own. Such handson practices, with instructor-provided rubrics and peer critique, illustrate the challenges of producing unbiased news and improve students' media consumption and production skills.

Erin Rowland (University of Tennessee, Knoxville) also stressed the importance of connecting theory to practical application. After teaching how different theories of public administration apply to organization structures, Rowland divided students into service-learning groups. Each group assigned leadership positions based on an application process, helping students get to know one another, facilitating group communication, and illustrating the ways in which administrative organizations delegate responsibilities.
Lutz Krebs (Maastricht University) took a similar approach to facilitating communication and cooperation among graduate students undergoing UN training in public policy. In order to overcome cultural divides, Krebs created heterogeneous groups designed to complement one another's strengths. This balancing of backgrounds and academic strengths produced a greater sense of camaraderie and increased students' willingness to seek peer and professor support.

Anas Malik (Xavier University) continued the theme of working collectively with people from different backgrounds by developing interfaith discussion groups to address collective action problems using "civic artisanship"-a shared understanding among people based on conventional obligations to out-group members rooted in a common commitment to "the golden rule." Such groups, rooted in a quest for mutual respect, understanding, and commitment, help to bridge cultural distance that may present a challenge to self-governance, thereby opening new possibilities for collective action.

Richard Battistoni (Providence College) also focused on the capacity for collective action. Battistoni teaches students about politics by asking students about the one thing they would most change about Providence College. Students then formed issue groups, met together outside of class throughout the year, set up specific goals for change, identified stakeholders, created power maps, and took action to change campus policy and practice. Students recognized the value of this approach to learning, and reported an increased willingness to engage in such collective action in the future, even when they did not achieve all of their goals.

Jodi Greene (Reading Area Community College) focused more narrowly on increasing students' voter registration rates and electoral engagement. By partnering with the League of Women Voters, Greene trained students to host voter registration drives and to reach under-represented groups including Latinos and students with disabilities. While training students to vote and teaching them to register and mobilize other voters is seldom part of an academic curriculum, panelists Kevin McGravey, Anna Flaherty, Harry Wessel, John Lovett, and Mary McHugh (Merrimack College) suggested that such specific training may be necessary if we want students to engage in the electoral process. They argued that even the most enriching (and student-appreciated) 
service learning activities do not necessarily promote increased electoral engagement. While service learning pedagogy may increase internal and external efficacy related to citizenship and community engagement, it will not translate to political engagement unless political scientists make such links explicit and give students an opportunity to practice political skills.

As members of the track worked through the concrete tools and steps in the workshop and studied the different approaches to civic engagement in the two panels, there was a deepening of skills, methods, and appreciation of the range of civic engagement opportunities, especially relating to the upcoming 2020 election.

\section{SIMULATIONS AND GAMES Mark D. Hamilton and Erica L. Seng- White}

The simulation and games track posited new ideas and critical questions about using active learning strategies in diverse classroom environments. Priority themes explored in the track highlighted the content, context, and ethics of such exercises. A primary goal of using simulations in the classroom is to connect the core content of political science to students' experiences: making questions of politics and power real to them. Simulations presented in this TLC track grouped around a pair of core concepts: 1) levels of analysis ("images") in international relations, and 2) collective action dilemmas.

Several presentations can be analyzed according to the three "images" (individual, state, and international system) explored in Kenneth Waltz's classic, Man, the State, and War. Probing at the individual level (Waltz's first image), Halit Tagma (Northern Arizona University) shared how he challenges students to analyze the body language of two strangers making small talk. This simple activity explored territoriality/personal space, providing a powerful visual for undergraduates learning about the individual level of analysis in IR. Moving to the state (Waltz's second image), Andrew Spath (American University) presented an innovative, multi-session, semi-online simulation called "Authoritania." The activity allowed students to choose their roles in society and explore results of their engagement with an authoritarian regime. Finally, a pair of presentations focused at the international level (Waltz's third image). Mert Kartal
(University of Wisconsin, Stevens Point) described a Model United Nations simulation used to enhance (and assess) students' understanding of global institutions. Jonathan Fanning (University of York) shared lessons from a counterfactual "Colonial Development Game" focused on strategy, geopolitics, and the limits of neoclassical economic theory. These simulations allow students to engage the complexity of politics from varied images/levels of analysis.

Another core concept in political science classrooms is the "collective action dilemma": the difficulty of organizing individuals and groups to cooperate in political projects. A pair of track simulations offered insights in this thematic arena. Victor Asal (University at Albany, SUNY), Nakissa Puneh Jahanbani (US Military Academy), Charmaine Noelle Willis (University at Albany, SUNY), and Christopher Linebarger (University of Massachusetts, Lowell) facilitated an interactive dice game that helps students understand why revolutions do not occur at a higher frequency. The inability of "peasants" to communicate and the coercive power of "lords" reduced likelihood of attacks against the leaders. Another collective action game focused on environmental sustainability. Mark Hamilton (Inter-American Defense College) used everyday items like goldfish crackers to help international military/diplomatic officials understand the "tragedy of the commons." Similar to levels of analysis, questions of collective action are activated and made real through simulations.

Several presentations centered on context and learning environment. Michael Murphy (University of Ottawa) stressed the importance of physical space and the challenges posed by traditional lecture halls. Classroom upgrades like moveable furniture, extra whiteboards, and mechanisms for projecting students' work were discussed as conducive to active learning. Another track presentation focused on doctoral student training and faculty development processes. Erica Seng-White and Michael Hunzeker (George Mason University) shared a pilot quantitative study that examines why (or not) professors incorporate simulations in class. Ideas emerged on how to broaden the study scope and access a larger faculty sample.

Other presentations considered how to extend the impact of simulations. Hamilton discussed four criteria that professors should consider in developing and implementing such activities: assessing the level of complexity, active learning model (experience-based reflection vs. problem-based learning), targeted benefits (content vs. process), and potential risks. Spath described a research extension for "Authoritania" in which students return post-simulation to mine activity logs from the website, develop original research questions, and learn to apply qualitative and quantitative analysis. Finally, Karta extended impact via assessment: pre- and post-testing of students' "deep learning" (factual, conceptual, procedural) about the UN system and growth in professional skills (negotiation, public speaking, etc.). Ultimately, these reflections on context complement earlier content discussion.

The final major theme engaged in track discussion centered on the ethics of active learning. Participants raised probing questions about classroom trust, student participation, and sensitivities/accommodations.

Regarding classroom trust, a concern arose about the impact of incomplete information employed in several of the presented simulations. Neither Hamilton nor Tagma informed students in advance about the actual objective of simulations, allowing this to emerge over the course of activities and in debrief sessions. Asal and his coauthors did not allow much communication among participants, and Spath limited the scope of information available during the actual simulation (prior to opening full access for the subsequent research component). Track discussants reflected on how lack of information could breed frustration and mistrust in some classrooms. Several participants focused on how

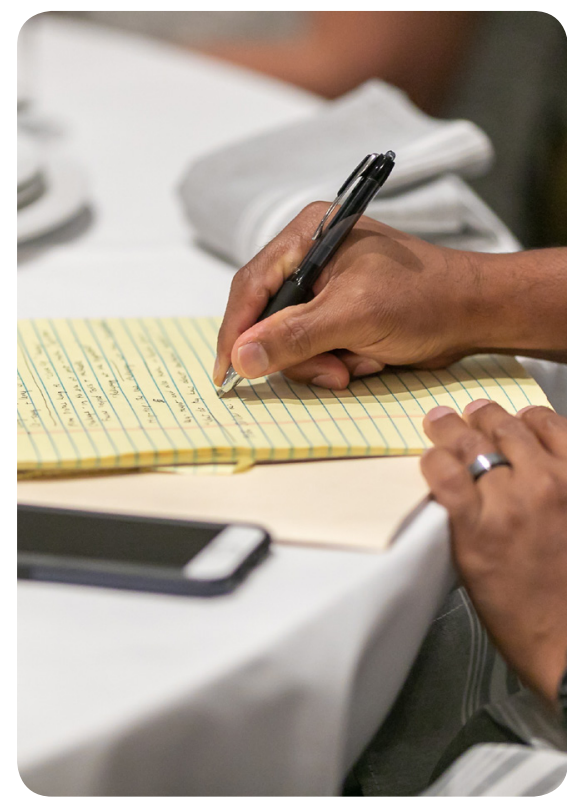


simulation-induced competition and peer assessment could morph into real-world conflict among students. Several track members highlighted the importance of debriefing to mitigate this challenge, and dedicating sufficient time and scope.

Regarding classroom participation, track members reflected critically on how to spark students' interest in simulations. Ideas included granting extra credit, replacing quiz grades, "bribing" with food, and leveraging popular culture. Debriefs (and in-process feedback for longer simulations) were highlighted as tools to better unite participants.

Finally, student sensitivities and accommodations were among the most fascinating ethical components raised. Faculty should reflect critically on cultural/religious implications, special needs, relational dynamics, and food allergies as they consider simulations. Attendees discussed the need for exit scenarios and accommodations. While the risk of harm is minimal in these specific simulations, ethical teaching and research practices demand careful attention by teaching faculty and may warrant external review in some cases. Ethical challenges and mitigation strategies should be a high priority for professors interested in the effective use of active learning.

The simulations and games track offered a host of new ideas on the content, context, and ethics surrounding active learning in political science education. Participants shared insights that contribute to a developing political science learning community specialized in pedagogy and andragogy.

\section{TECHNOLOGY AND INNOVATIVE PEDAGOGY IN THE CLASSROOM}

\section{Erin Richards, Jeffrey Carroll, and Shane Nordyke}

Educators often face challenges in finding meaningful ways to engage with students. Hence, faculty are searching for innovative ways to reach their students without sacrificing student learning. As the topics of the technology and innovative pedagogy in the classroom track panels suggest, the presentations focused on creative ways to utilize technology to increase student participation and engagement.

Participants in this track presented an assorted array of technological or innovative approaches with the aim of enhancing participation and engagement in political science. The broad umbrella of our track allowed us to address a variety of challenges including providing support to students who are intimidated to speak in class, creating space for alternative mediums of communicating or expanding access to regions of the world. To meet these challenges, the presenters proposed tools including memory techniques, "alternative" methods for students to express their mastery of material through the marriage of music and poetry, the use of open educational resources (OERs), alternative methods for mentoring underrepresented groups, and worldwide virtual classrooms.

In the first panel, Cole Spitzack, Michael Wright, Sean McMahon, and Dale Hommerding (all from the US Military Academy), along with George Fust (US Army) talked about the role of memory exercises in improving student performance. Jeffrey Carroll (Chestnut Hill College) and Carrie R. Humphreys (University of Tennessee, Martin) introduced innovative ways to engage students in political and theoretical dialogue through a hip-hop digital space and in-class improv (respectively). Kyeonghi Baek, Mehwish Sarwari, and Peter R. Yacobucci (all from SUNY, Buffalo State) discussed how teachers might use open educational resources to encourage student engagement.

In the second panel, Anita Chadha (University of Houston), Youngmi Kim (University of Edinburgh), and Matteo Fumagalli (University of St. Andrews) addressed the role of digital engagement and online learning. Andra Olivia Miljanic (University of Houston) talked about how to empower women in political science education, while Adam H. Hoffman and Sarah Surak (both from Salisbury University) explained how to use voter guides in class.

The presenters spurred participants to think about two larger challenges. First, could the approaches work in other contexts beyond their individual experience? Could a practice aimed at undergraduate students also apply to graduate students? Could a classroom exercise designed for 20 students work in a 200-student lecture? Could an activity designed for one underrepresented group work for a different underrepresented group? Second, did the innovations result in the learning outcomes we hope to achieve as political science educators? While the use of alternative methods may allow for students to participate and engage with material in different ways, is the learning that occurs as deep and long lasting as outcomes using more traditional methods?
Finally, participants recognized that, going forward, it is important to think about equity-some tools expand access for some while diminishing it for othersand aligning practices with research on how students learn in the twenty-first century.

\section{DIVERSITY, EQUITY, AND}

\section{INCLUSION}

\section{Megan Becker}

Diversity is both a reality and a goal on college campuses. More people are going to college and they are coming from a greater variety of backgrounds and experiences, a change that many of us see reflected in our classrooms. We also see room for improvement. If our work as educators is to develop society's next generation of leaders, then we must ensure that higher education is made accessible to all. We must ask ourselves: how do we make sure that our students feel welcome and valued as members of our learning communities? How can we support them and help them achieve their goals? As our student bodies become more diverse, it is incumbent upon us to foster an inclusive environment, using our positions of power to address the needs of all students in our syllabi, our classroom practices, our curricula, and on our campuses. Participants in the diversity, equity, and inclusion track wrestled with these issues, sharing their challenges and their practices.

Presenters asked us to re-assess the readings we assign, the assignments we give, and the relationships we have with our students. As Jonneke Koomen (Willamette University), Patrizia Longo (Saint Mary's College of California), and Karen Wright (University of Glasgow) discussed in their respective presentations, no matter our subfield, we must make efforts to "decolonize" our syllabi and add underrepresented voices to our reading lists. Beyond that, we can contextualize the canon, discussing why certain voices are dominant. We can interweave discussions of race, gender, and class into our discussions, not relegate them to a single week in a survey course.

In our classroom, we can use media like documentaries, as Pia A. Knigge (Auburn University, Montgomery) discussed, to offer a counter-narrative to a telling of American history that frequently privileges the story of the majority over the minority. Having students consider their own biases encourages them to have empathy for others and be more tolerant in their opinions and actions. We can highlight the intersectional identities that shape individuals' 
experiences of the world and emphasize a sense of shared humanity.

We must also recognize that students with diverse backgrounds may struggle with the hidden curriculum of higher education. Andrew Hewitt Smith (University of Texas, Rio Grande Valley) suggested that we cannot assume that all students have the same level of preparation or the same understanding of academic expectations and need to be proactive in assessing these challenges and addressing them with clear assignments, transparent grading practices and a curriculum that allows for the development of skills over time.

We might also challenge our own understanding of expertise. As faculty, we have been trained to see education and credentialing as the primary signifiers of expertise. This frequently overlooks the power of experience. Lived experience is a form of knowledge and we must be careful not to dismiss it. Our job is to give students frameworks to make sense of their own experience and that of others-how to fit the personal into a broader context.

Another theme that emerged was looking beyond the time we have with our students while they are in our classes, coming up with creative ways to create a pipeline from our communities to our campuses and from our campuses into politically-engaged careers. Alison Rios Millett McCartney (Towson University) and other presenters offered models for programs, such as Model UN, that bring students from local high schools to campus for a series of events centered around political issues. This type of early engagement can be critical for first-generation college students, allowing them to see themselves as future members of a campus community.

Similarly, we need to be mindful of how the climate we foster on campus is preparing our students for their lives as politically engaged citizens. As J. Cherie Strachan (Central Michigan University) asked: how do we assure that, in an era of "rude politics," they feel empowered to be a part of the political process and see themselves as future leaders? We need to consider how we can counter political messages that may cause certain students to become disengaged.

The discussion amongst attendees focused on action-how can we take what we've learned and put it in to practice back on our own campuses? Participants shared resources and brainstormed ways to overcome potential obstacles in the classroom, such as avoiding tokenizing students from underrepresented groups and not expecting them to speak for others or putting the onus on them to teach other students.

Sustained change requires more than just adjusting what we do in the classroom; it requires institutional change and resources to support it. It is incumbent upon faculty and administrators to make sure that a broad swathe of people is involved in addressing these issues and that the process incorporates diverse voices without overtaxing participants from underrepresented groups. We must advocate for resources (both from our colleges and grant-making organizations) to support change, so that programs have the financial backing they need to be successful and that faculty are rewarded for their work in this area. We must design assessments that allow us to measure the impact of our programs, so that we may demonstrate their value and identify areas for improvement. As political science faculty teaching the next generation of leaders in politics and policy, we have an important role to play in this process.

\section{CONCLUSION}

The 2019 TLC at APSA continued the tradition of highlighting innovative scholarship on teaching and learning while fostering collaborative and professional networking opportunities for participants. With the subtle changes in the format, attendance remained strong throughout the day-long event. Post-conference evaluations will identify possible innovations and improvements for future meetings. We are grateful for this opportunity to serve our peers and the discipline and are thankful to all who participated in the 2019 TLC at APSA. We look forward to the third iteration of TLC at APSA in 2020.

\section{REFEREN C E S}

McCartney, Alison Rios Millett and Renee Van Vechten. 2019. "Teaching and Learning Conference-within-a-Conference Launched at APSA Annual Meeting in Boston," PS: Political Science and Politics 52 (1): 157-8.

Waltz, Kenneth. 1959. Man, the State, and War: A Theoretical Analysis. Columbia University Press.

\section{Call for Papers: PS Symposium on Strategies for How Men Can Advance Gender Equity in Political Science}

G uest editors Rebecca D. Gill and Daniel J. Mallinson are proposing a $P S$ symposium that builds on the work of the 2018 APSA Diversity and Inclusion Hackathon. They are seeking short papers, no more than 1,500 words, that address one or more of the 10 categories brainstormed at the hackathon track on men advancing gender equality in political science: advocacy/recognize achievements; inclusive networks; women in positions of power (e.g., journal editors); stand up; respect and know gender research/diversify syllabi; build better systems; check privilege, check biases; hire more women; avoid "manels" and model behavior; and transparency on conditions.

The guest editors are particularly interested in articles written by diverse teams of scholars, including scholars with various marginalized identities, scholars of varying rank (particularly senior male colleagues), and genders. This is an opportunity for men in the profession to help chart a way forward as advocates for inclusiveness. The symposium is intended as a collaborative effort aimed at improving the climate within political science.

Please submit an abstract that situates your contribution within the framework developed at the hackathon, noting the aforementioned category or categories your paper will address. More information about the hackathon track is available at: https://tinyurl.com/apsahackathon-what.

Abstracts are due February 1, 2020, with full papers due by March 13. If you are interested in contributing on a topic, but do not have a team to work with, we are happy to connect scholars of similar interests. Contact Daniel J. Mallinson and Rebecca D. Gill at mallinson@psu. edu and rebecca.gill@unlv.edu. 